\title{
RELATIVISMO ÉTICO Y JUSTIFICACIONES MORALES
}

1

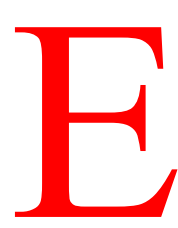

ntiendo que a Ernesto Garzón no le gustan nada aquellas acciones políticas o aquellas ideologías que, a su entender, pretenden pasar por alto razones últimas de justificación, razones que suelen calificarse de principios morales ${ }^{1}$. Puesto que involucrando las acciones políticas, como muchos actos estatales el recurso a la violencia o procedimientos reñidos con la «moral ordinaria» o con la «moral privada», pareciera que sólo cabría aceptarlos de contar con alguna justificación suficiente. Como sería circular pretender fundar las acciones políticas en contingentes directivas políticas -error al que induce el maquiavelismo-, y como los criterios políticos no podrían ser considerados fundamentos últimos de justificación, correspondería buscarle justificación moral. Así, señala Garzón, «si lo que se quiere decir es que el ámbito de la política escapa a toda valoración moral, ello significaría admitir que hay un enorme campo de acciones voluntarias con respecto a las cuales no tendría sentido predicar su calidad moral». Y continúa: «Una restricción de este tipo contradice abiertamente las más elementales experiencias cotidianas ya que no es un sin sentido afirmar que la acción A es una acción política y preguntarse si está justificada moralmente»².

Pero parece claro que el que quepa decir de un acto que es una acción política y que, con respecto al mismo, también quepa preguntarse si tiene justificación moral, no acredita la tesis subyacente más fuerte de que toda acción política necesariamente se funda en principios morales o, quizás, de que toda acción política debe estar moralmente justificada. Pues Garzón sostiene que «si se quiere hablar de justificación política, ello tiene que ser entendido como una especie de la justificación moral» ${ }^{3}$.

Por lo común, los actos políticos suelen invocar como fundamento suficiente normas jurídicas positivas, o algún otro elemento integrante de lo que se entienda por derecho (como los manidos principles and policies de Dworkin). Esta forma de fundamentación, aunque retóricamente eficaz, no parece satisfactoria. Si se considera, como haría cualquier buen kelseniano, que toda norma jurídica es también expresión de una voluntad

\footnotetext{
${ }^{1}$ Ernesto Garzón Valdés, «Moral y política», en Anuario de Filosofía del Derecho, Madrid, 1984, p. 180.

${ }^{2}$ Ibid., p. 182.

${ }^{3}$ Ibid., p. 183.
} 
política -en cuanto las normas constituyen el sentido de actos volitivos y éstos, en cuanto decisiones, son acciones políticas-, tendríamos que pensar que una acción política está jurídicamente justificada, se incurre en el círculo lógico anteriormente mencionado y, lo que es peor, se recurre a una ideología destinada a disimular bajo una terminología legal el crudo ejercicio del poder. Esta ideología constituiría una forma del positivismo ideológico que denunciara Bobbio: «La política se regiría por normas y reglas de juego que otorgan la debida justificación autorizando la realización u omisión de ciertos actos. En la jurisprudencia esta posición suele ser llamada 'positivismo ideológico'. Examinada más de cerca se nota que la invocación de las normas... de los distintos sistemas normativos no puede proporcionar la justificación de estas normas o sistemas. La descripción de las normas supremas de un sistema normativo no basta para justificar moralmente las acciones que se realizan de acuerdo con ellas. El que un político considere que por razones políticas se debe hacer A y ordene A no puede ser aducido como justificación de que debe hacerse A. Se trata aquí de hechos (la creencia del político y su decisión de ordenar A) que no pueden servir de premisas justificativas de un razonamiento práctico. Avanzar por esta vía nos conduce fatalmente a caer bajo la guillotina de Hume al haber confundido el plano del ser con el del deber ser» ${ }^{4}$.

¿Es correcta esta argumentación? En un razonamiento práctico -esto es, aquel argumento cuya conclusión contiene una directiva reguladora o motivadora del comportamiento del sujeto- es indispensable que por lo menos una de las premisas no redundantes sea un enunciado normativo; esto es: todo razonamiento práctico contiene un ingrediente normativo en el conjunto de enunciados empleados como premisas. Que esa norma se haya originado en la orden dada por un político y que éste haya sustentado la creencia de que tal norma debe instaurarse mediante una decisión suya, son cosas que hacen a la existencia efectiva de la norma en un sistema social. Esos hechos, sin embargo, no integran el argumento deductivo y por tanto no llevan al error lógico de pretender inferir una conclusión normativa de puras premisas fácticas. Al fin y al cabo, toda premisa con carácter normativo se origina en algún acto intencional, pero el hecho en que la norma encuentra origen no transforma el carácter normativo del enunciado. Para aceptar normas que no provengan de actos de voluntad -para conservar la terminología tradicional-, habría que recaer en la manida referencia a normas originadas en la naturaleza de las cosas, actitud ideológica que justamente Garzón se ocupó de desenmascarar minuciosamente ${ }^{5}$. Parece difícil que, so pretexto de denunciar el positivismo ideológico o el maquiavelismo de quien funde sus acciones políticas en normas de derecho, se incurra

\footnotetext{
${ }^{4}$ Ibid., p. 183/4.
}

${ }^{5}$ Ernesto Garzón Valdés, «Derecho y naturaleza de las cosas», I y II tomos, Universidad de Córdoba, Argentina, 1970. 
en tesis ontológicas tan aventuradas como, por ejemplo, la sostenida, entre los moralistas clásicos, por R. Cudworth: «Ningún imperativo (command) positivo puede hacer moralmente buena o mala a una cosa cualquiera, o justa o injusta, si la naturaleza no la ha hecho tal previamente... Por lo cual en los imperativos positivos, la voluntad de la autoridad (commander) no crea ninguna nueva entidad moral, sino que solamente modifica de diversas maneras y determina el deber $u$ obligación general $u$ obligación de justicia natural de obedecer a la autoridad legal y de respetar lo prometido bajo juramento o por convenio... $\mathrm{y}$, por ende no hay cosas nuevas justas o debidas resultantes de tales, fuera de lo que siempre fue tal por su naturaleza.... ${ }^{6}$. Esta tesis tiene, en autores como el mencionado, una fundamentación metafísica tradicional: «Y puesto que una cosa no puede convertirse en cualquier otra por un acto de mera voluntad, sin tener entidad o naturaleza, toda cosa tiene que estar necesaria e inmutablemente determinada por su propia naturaleza $\iota^{7}$, naturaleza que proviene de una decisión divina. Aún un filósofo propenso a creer en esencias inmutables y necesarias, como Husserl, criticó semejantes formas de pensar en terreno moral: «Tal postura llevó a Cudworth... a considerar lo ético como de alguna suerte análogo a lo matemático, pues las propiedades que los fenómenos morales tienen, por naturaleza inmutable, (serían) parejas a las propiedades de objetos ideales como los números»; «estos dominios de objetos -continúa Husserl- comportan diferencialmente. Quien niega una ley material incurre en error; quien contraria, en cambio, una ley moral incurre en algo así como pecado. Y error y pecado no son conceptos intercambiables o asimilables: una ley moral puede ser tenida por verdadera $y$, sin embargo, actuarse contra ella, lo que es impensable de una ley matemática o física verdaderas» ${ }^{8}$.

Sería excesivo atribuir a los muchos pensadores contemporáneos que, quizás frustrados por amargas experiencias políticas, buscan borrar la histórica distinción entre derecho (o política) y moral, una ontología platonizante de cuño religioso como la traída a colación como ejemplo histórico. Pero tampoco habría que pasar por alto la impresión de que, en muchos de tales pensadores, al renovado recurso o una fundamentación moral sugiere una suerte de nostalgia religiosa, cuando no una recaída en creencias irracionales. En Garzón, me parece, fuera de la comprensible repugnancia que le suscita la arbitrariedad (i.e., en su terminología: la inmoralidad) de muchas políticas, la cuestión de la insuficiencia de la mera fundamentación jurídica de los actos políticos resulta de una tesis más bien epistemológica: las acciones, como datos fácticos, no son

\footnotetext{
${ }^{6} \mathrm{R}$. Cudworth, «A treatise concerning eternal and immutable morality», libro I, cap. 2 \& 5 (en D.D. Raphael, «British moralist», Clarendon Press, Oxford, tomo I).

${ }^{7}$ Ibid., I, 2 \& 3.

${ }^{8}$ R. J. Vernengo, «La ética de Husserl», Universidad de Buenos Aires, Fac. de Derecho, 1967, p. 32; cf. también J.C. Hage, «The objetivity of value judgements», Rechtstheorie 17 (1986).
} 
razones suficientes de autojustificación, puesto que toda justificación es un discurso normativo. Este, para no convertirse en circular o en inconclusivo, requiere de principios últimos normativos que sirvan de definitivo criterio de fundamentación de la decisión práctica que se adopte $\mathrm{y}$, por ende, de las acciones emprendidas. Como parece claro que ninguna norma o conjunto de normas de un derecho positivo pueden ser tenidas por tales principios últimos, atento el carácter históricamente contingente de las regulaciones jurídicas, correspondería postular que son principios morales «las razones últimas de justificación de las acciones» ${ }^{9}$, donde me interesa subrayar la característica de «últimas» atribuidas a las razones que puedan servir de fundamento de cualquier acción.

2. De ahí que la efectiva bête noire de Garzón en ese terreno no lo sean ni el positivismo ideológico (un pecado en que rara vez incurren los juristas y que ignoran los políticos), ni el maquiavelismo (estrategia que es difícil adoptar expresamente, pues aun el más duro de los autócratas guarda alguna sensatez), sino el relativismo ético. Conviene en este punto referirse al conocido ensayo de I. Hedenius que Garzón menciona frecuentemente ${ }^{10}$.

Hedenius señala que constituye relativismo ético sostener que algo sea $\mathrm{P}$ y que algo no sea $\mathrm{P}$ (donde $\mathrm{P}$ es un predicado ético, sin que importe quién sostenga la tesis afirmativa y quién, su negación), sin aceptar que «se da una efectiva contradicción y que tanto uno como los oponentes pueden estar igualmente acertados» ${ }^{11}$. Los valores de verdad de los enunciados, claro está, son constantes, en el sentido de que si una proposición es verdadera (o falsa) es siempre verdadera (o falsa), en el sentido sencillo de que todos los ejemplares del enunciado que expresa a una misma proposición tienen el mismo valor de verdad. Es imposible que una misma proposición sea a veces verdadera y a veces falsa; a lo sumo, puede darse que en algunos casos un enunciado, empleado anteriormente para expresar la proposición verdadera, sea usado para expresar otra proposición falsa. Pensar que una proposición y su negación son ambas verdaderas implica repudiar el principio de contradicción y, por ende, apartarse de una lógica «necesaria para cualquier pensamiento racional o científico» ${ }^{12}$. Igual regla cabe aplicar a todo «sistema aceptable de lógica deóntica», es decir, a enunciados normativos, salvo que ahí la propiedad característica será la de validez y no la de verdad: «todos los ejemplares de un enunciado normativo que expresen la misma norma tienen el mismo valor de validez» ${ }^{13}$. En este sentido, no hay ni

\footnotetext{
${ }^{9}$ E. Garzón Valdés, «Moral y política», loc. cit., p. 180.

${ }^{10}$ Ingemar Hedenius, «On relativism in ethics», Theoria XLVII (1981).

${ }^{11}$ Ibíd., 122.

${ }^{12}$ Ibíd., p. 123.

${ }^{13}$ Ibíd., p. 124.
} 
enunciados cuyo valor de verdad sea relativo, ni normas cuya validez también lo sea.

En el terreno de la ética, cabría distinguir, propone Hedenius, entre un relativismo relativo a las proposiciones externas sobre una moral y un relativismo referente a los juicios normativos internos, sobre qué sea bueno o malo. Las proposiciones externas sólo son «relativas» en el sentido trivial de que una norma, considerada idéntica por recibir expresión idéntica, puede ser válida en una sociedad e inválida, en otra: «no puede surgir problema lógico alguno del hecho banal de que las costumbres e ideas morales a veces son diferentes en sociedades diferentes» ${ }^{14}$. En su uso interno, las normas morales son usadas en su función social (por ejem plo, de control), y expresan juicios morales de los actores e intervinientes en acciones. Estos juicios morales tienen emisores y receptores, sujetos que muchas veces no son expresamente indicados en la formulación verbal del juicio. Los juicios morales internos son muchas veces elípticos en su formulación, sea ésta de función prescriptiva o puramente evaluativa. La relatividad postulada de algunos juicios morales internos resulta de su formulación incompleta; basta dar expresión a los sujetos emisor o receptor de la norma para que se advierta que carece de sentido pensarlas como válidas o inválidas relativamente.

Parece a veces que por estar dirigidas ciertas normas a grupos limitados, se planteará la cuestión de la invalidez de la norma universal formulable. Que todos los ciudadanos suecos tengan el deber jurídico de pagar impuestos, mientras el rey está exento de esa obligación, haría pensar en que la norma en cuestión fuera de validez relativa. Pero la tesis de la universalidad (posible) de los juicios morales, no debe confundirse con la supuesta generalidad de muchas normas jurídicas. El hecho de que muchas reglas morales estén dirigidas a grupos limitados ni impide su universalización, mediante el recurso a conocidas triquiñuelas de lógica formal, ni las convierte en relativas (en el sentido de que pueden ser tenidas por válidas e inválidas de consuno).

Las normas, como es sabido, pueden ser usadas en función prescriptiva, para modificar conductas de los receptores del mensaje prescriptivo; pero también pueden ser usadas sin propósito prescriptivo, como en el caso de las Rechtssätze kelsenianas, donde sólo se pretende transmitir una información sobre el carácter normativo que cierta acción tenga en cierto grupo social, conforme a cierto código normativo reconocido. En ese segundo uso, las normas pueden parecer relativas, como juicios morales internos contrafácticos. Un antropólogo, sugiere Hedenius, podría afirmar que «la acción A es buena (debida) cuando la practica la sociedad X, pero sería mala si fuera practicada por la sociedad $\mathrm{Y} \gg{ }^{15}$. Se trata, con todo, de enunciados elípticos, cuando no defectuosamente formados, que una vez reconstruidos no resultan relativos en modo alguno. Es verdad, cabe apuntar, que las normas morales y jurídicas, formuladas

\footnotetext{
${ }^{14}$ Ibíd., p. 125.

${ }^{15}$ Ibíd., p. 129.
} 
en lenguaje natural, no cuentan con reglas de formación explícitas y finitas, de donde cabe concluir que la eliminación de las elipsis que propone Hedenius no son comprensibles sin remisión a esas reglas de formación faltantes ${ }^{16}$.

La tolerancia moral, subraya Hedenius y entiendo que el argumento es importante y atendible, no acarrea la relatividad de las normas toleradas; éstas continúan siendo válidas o inválidas, sin relativismo contradictorio alguno, de igual manera que el derecho del hombre sobre la libertad de expresión «no significa que todas las opiniones que se toleran socialmente, deben ser tenidas por igualmente verdaderas o válidas». Otra cosa llevaría a «una parodia de lo que debe ser un razonamiento ético» ${ }^{17}$.

Garzón piensa que, en derecho o en política, por estar en juego el ejercicio de la violencia, que «no es nunca un acto gratuito o indiferente», la justificación moral «no puede agotarse en establecer la concordancia de su uso con las normas vigentes en una sociedad dada». «Esta suele ser -recuerda- la posición adoptada por el relativismo ético, que tropieza con serias dificultades lógicas cuando pasa al nivel de una ética normativa y no se agota en los enunciados descriptivos verdaderos de que en diferentes sociedades y épocas rigen o han regido normas éticas diferentes». En rigor, de atenernos a la propuesta de Hedenius a la que Garzón remite, más que dificultades lógicas se trataría, en rigor, de una defectuosa formación de los enunciados que se pretenden verdaderamente válidos, aunque contradictorios. Esta suerte de relativismo se remedia fácilmente con una formulación menos pobre expresivamente de las normas en cuestión. Y salvo para quien tome en serio aquel dictamen de Pascal sobre el efecto de los Pirineos sobre la justicia de las normas, no parece que atañe al relativismo más enérgico que ha sustentado, por ejem plo, Kelsen con respecto de los valores jurídicos.

Se trata de aquel relativismo axiológico que ha sido interpretado como una directiva escéptica con respecto del conocimiento (por llamarlo así) de preceptos jurídicos o morales en su uso prescriptivo. Si se acepta, como es corriente, que los enunciados normativos, en función prescriptiva, son alógicos por carecer de propiedades hereditarias lógicamente, como sucede típicamente con la validez en sentido no descriptivo, parece claro que ninguna norma jurídica, pero tampoco ninguna norma moral, puede funcionar como premisa constitutiva de la «razón última de justificación de las acciones». Es que ya no se trata del relativismo consistente en que «todo orden jurídico, cualquiera sea su contenido, se justifica por sí mismo y debe ser obedecido», esto es, del positivismo ideológico identificado ahora y confundido con un relativismo de fundamentación,

${ }^{16}$ R. J. Vernengo, «About some formation rules for legal languages», en S. Engel y R.A. Métall, «Law, state and international legal order. Essays in honor of H. Kelsen», U. of Tennesee Press, 1964.

${ }^{17}$ I. Hedenius, op. cit, pp. 130/1. 
sino de un relativismo epistemológico, que estima que las razones morales, que deberían servir de fundamentos últimos de justificación, son puramente «subjetivos o relativos» ${ }^{18}$. Aquí relativismo es con fundido con subjetivismo, en el sentido de que la verdad de un enunciado o la validez de un precepto son dependientes de características del sujeto cognoscente, al cual la norma está dirigida. Sin embargo, este criterio de relativismo normativo -aquél que estima que la validez de una norma depende de su aceptación o reconocimiento por el sujeto obligado- no ha sido sustentado por la teoría política o la filosofía jurídica, que, por lo general, consideran irrelevantes tales actitudes de parte de los receptores de los mensajes normativos. Garzón señala, como se indicó arriba, que en el razonamiento práctico figurarían erróneamente, de incurrirse en positivismo ideológico (i.e.: en relativismo ético), las creencias sobre la validez de la norma que sustente su creador (la autoridad política). Pero es claro que no podría entenderse que hay «decisión de ordenar» alguna, por parte de la autoridad, si ésta sustentara la creencia de que la norma es válida conforme las valoraciones del sujeto recipiendario de la prescripción. ¿Qué orden sería aquélla en que el político dijera: te ordeno hacer A, siempre y cuando tengas ganas de hacer A? Esta suerte de relativismo ético ciertamente no conduce, como supone catastróficamente $\mathrm{Nino}^{19}$, al caos, la anarquía y la violencia, de ser «coherentemente llevada a la práctica por gentes con opiniones diversas», sino que simplemente lleva a una mayor situación de libertad, si por tal entendemos una situación en que el ámbito de las conductas facultativas se ve incrementado.

3. Quizás sea conveniente distinguir cuando se habla de relativis mo ético o axiológico, el relativismo ético como un principio metaético (como, por ejemplo, cuando Kelsen sostiene la acientificidad del conocimiento valorativo), del relativismo como una tesis ontológica referente a la existencia objetiva de hechos morales o de valores en sí. El relativismo, como subjetivismo, acepta ambas interpretaciones.

Estas variantes no significan incurrir en un escepticismo teórico y práctico estéril. Implican delimitar el ámbito efectivo en que ciertos tipos de conocimiento, como el de la jurisprudencia dogmática, se cumplen, de otros, como el de las normas morales, en que no existen ciencias paradigmáticas normales. Ello apunta a que en ese dominio no se ha constituido un campo objetivo y un marco conceptual generalmente aceptado, pero no significa negar la existencia de datos valorativos, morales u otros. Dado que no existe un conocimiento objetivo, intersubjetivamente válido, de los fenómenos morales, parece utópico referirse a ellos como fundamento último de justificación. En otros términos: la teoría elabora conceptualmente datos captados precientíficamente, sea en una supuesta intuición moral o en una experiencia ética especial; esos datos preteóricos nunca pueden ser fundamento último de la verdad o validez de los enunciados de la teoría científica.

\footnotetext{
${ }^{18}$ C. S. Nino, «Democracia y verdad moral», La Nación, Buenos Aires, 1 de junio de 1986.

${ }^{19}$ Ibíd.
} 
S. Fishkin ha propuesto un interesante análisis de los relativismos morales ${ }^{20}$. En una forma extrema, el relativismo ético declara imposible a todo juicio moral. Una forma más atenuada sostiene que, aunque posible, no debe formularse juicios morales. Éstos, de darse, sólo podrían referirse al sujeto que lo pronuncia, pero no a terceras personas. Por fin, un relativismo ético muy atenuado sólo aceptaría los juicios morales referentes a otros si se efectúan ateniéndose a los valores propios de ellas, y no de quien efectúa el juicio. El relativismo axiológico o ético sólo aceptaría que los juicios morales son válidos para el sujeto que los enuncia y son susceptibles de aplicación inter-subjetiva. Los enunciados morales (axiológicos), para el relativista descrito por Fishkin, negaría la posibilidad de generalizarlos (en el sentido kantiano), así como toda pretensión de verdad. Como intenta demostrar Fishkin, este relativismo, si bien podría impedir una elaboración científica de un material normativo, no impide una consideración racional de los problemas morales, jurídicos y políticos.

Parece claro que mientras no se tracen nítidas distinciones entre estas variedades de relativismo ético o axiológico, el decidirse, como única posibilidad restante, por la moral (¿por alguna moral? o, ¿por algunas morales?), como razón última de justificación de toda acción, es una actitud un tanto desesperada, como la del náufrago que echa mano de cualquier tabla de salvación. Sugerí que así se expresa una inquietud religiosa. O, quizás, una huida ante el nihilismo.

La definición clásica del nihilismo, propuesta por Nietzsche, es la de aquel punto de vista que en todos los casos interpreta a las cosas (a los entes) como valores. Y éstos, como manifestación de una voluntad de poder. Desde un punto de vista ontológico, el nihilismo exige que toda verdad entitativa sea reducida a juicios de valor. Es versión frecuente la que ve en el relativismo ético o, más precisamente, en el relativismo ontológico la forma actual del nihilismo; también, claro está, siempre se ha dicho que el subjetivismo gnoseológico es una de las manifestaciones típicas de ese denostado nihilismo. Pero Nietzsche, que algo sabía al respecto, había señalado que la constitución teórica de sus objetos por las ciencias modernas es justamente la forma en que el nihilismo se revela fundamentalmente en nuestros tiempos. Estas tesis metafísicas presuponen un criterio de la verdad como correspondencia ${ }^{21}$.

Tengo para mí que la actitud reciente de muchos pensadores (sobre todo en el campo del derecho y la ética), en que aparece un repudio ante el relativismo axiológico y la pretensión de buscar razones últimas, fundamentos últimos para los conjuntos de normas sociales positivas -fundamentos que se buscan en supuestos hechos morales o en principios que aspiran a ser instancia final de justificación de las acciones constituye manifestaciones de aquel nihilismo que Nietzsche apuntara.

\footnotetext{
${ }^{20}$ S. Fischkin, «Ethical reasoning and political philosophy». Yale University Press.

${ }^{21}$ R.J. Vernengo, «Wertrelativismus und Rechtswissenschaft», a aparecer en Rechtstheorie.
} 
De ahí, creo, que el problema de la racionalidad vuelva a estar sobre el tapete ${ }^{22}$. Véase esas líneas de Garzón: «Cuando en lo que siga se haga referencia a una ética racionalmente aceptable, por racionalidad habrá de entenderse la posibilidad de formular algunos principios que puedan ser aceptados como justificación final, es decir, desde el punto de vista moral, o por cualquier individuo imparcial y racional» ${ }^{23}$. Destaco la modestia de la pretensión: se trata sólo de «algunos» principios cuya formulación quizás sea «posible». Destaco, sobre todo, que dichos principios de «justificación final» no son sino valores morales. La racionalidad se identifica con el nihilismo, en cuanto la verdad es vista como un mero valor.

de 1987

Buenos Aires, noviembre

${ }^{22}$ G. von Wright, «Vetenskapen och förnuftet», Söderström förlags, 1986.

${ }^{23}$ E. Garzón Valdés, «Moral y política», loc. cit., p. 190. 